\title{
Current Cigarette Smoking Among Adults — United States, 2016
}

\author{
Ahmed Jamal, MBBS ${ }^{1}$; Elyse Phillips, $\mathrm{MPH}^{1}$; Andrea S. Gentzke, $\mathrm{PhD}^{1}$; David M. Homa, $\mathrm{PhD}^{1}$; Stephen D. Babb, MPH${ }^{1}$; \\ Brian A. King, $\mathrm{PhD}^{1}$; Linda J. Neff, $\mathrm{PhD}^{1}$
}

The U.S. Surgeon General has concluded that the burden of death and disease from tobacco use in the United States is overwhelmingly caused by cigarettes and other combusted tobacco products (1). Cigarettes are the most commonly used tobacco product among U.S. adults, and about 480,000 U.S. deaths per year are caused by cigarette smoking and secondhand smoke exposure (1). To assess progress toward the Healthy People 2020 target of reducing the proportion of U.S. adults aged $\geq 18$ years who smoke cigarettes to $\leq 12.0 \%$ (objective TU-1.1), * CDC analyzed data from the 2016 National Health Interview Survey (NHIS). In 2016, the prevalence of current cigarette smoking among adults was $15.5 \%$, which was a significant decline from 2005 (20.9\%); however, no significant change has occurred since 2015 (15.1\%). In 2016, the prevalence of cigarette smoking was higher among adults who were male, aged 25-64 years, American Indian/Alaska Native or multiracial, had a General Education Development (GED) certificate, lived below the federal poverty level, lived in the Midwest or South, were uninsured or insured through Medicaid, had a disability/ limitation, were lesbian, gay, or bisexual (LGB), or had serious psychological distress. During 2005-2016, the percentage of ever smokers who quit smoking increased from $50.8 \%$ to $59.0 \%$. Proven population-based interventions are critical to reducing the health and economic burden of smoking-related diseases among U.S. adults, particularly among subpopulations with the highest smoking prevalences $(1,2)$.

NHIS is an annual, nationally representative in-person survey of the noninstitutionalized U.S. civilian population. The NHIS core questionnaire is administered to a randomly selected adult in the household (the sample adult). In 2016, the NHIS was administered to 33,028 adults aged $\geq 18$ years;

\footnotetext{
*https://www.healthypeople.gov/2020/topics-objectives/topic/tobacco-use/ objectives.
}

the response rate was $54.3 \%$. Current cigarette smokers were respondents who reported having smoked $\geq 100$ cigarettes during their lifetime and were smoking every day or some days at the time of interview. Former smokers were respondents who reported having smoked $\geq 100$ cigarettes during their lifetime but were not smoking at the time of interview. The mean number of cigarettes smoked per day was calculated among daily smokers. Quit ratios were defined as the ratio of former smokers to ever smokers (i.e., persons who had smoked $\geq 100$ cigarettes during their lifetime).

Data were weighted to adjust for differences in the probability of selection and nonresponse and to provide nationally representative estimates. Current smoking was assessed overall

\section{INSIDE}

60 Asthma Mortality Among Persons Aged 15-64 Years, by Industry and Occupation - United States, 1999-2016

66 Attention-Deficit/Hyperactivity Disorder Medication Prescription Claims Among Privately Insured Women Aged 15-44 Years — United States, 2003-2015

71 Respiratory Syncytial Virus Seasonality — United States, 2014-2017

77 Notes from the Field: Legionellosis Outbreak Associated with a Hotel Aquatics Facility Tennessee, 2017

79 Notes from the Field: Baylisascaris procyonis Encephalomyelitis in a Toddler - King County, Washington, 2017

82 QuickStats

Continuing Education examination available at https://www.cdc.gov/mmwr/cme/conted_info.html\#weekly.

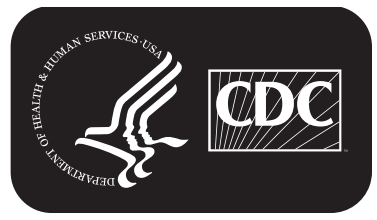

U.S. Department of Health and Human Services Centers for Disease Control and Prevention 
and by sex, age, race/ethnicity, education, poverty status, ${ }^{\dagger}$ U.S. Census region, ${ }^{\circledR}$ health insurance coverage at the time of survey, ${ }^{9}$ disability/limitation status, ${ }^{* *}$ sexual orientation, ${ }^{\dagger \dagger}$ and presence or absence of serious psychological distress. ${ }^{\$ \$}$

\footnotetext{
${ }^{\dagger}$ Based on reported family income and family size: 2005 estimates are based on reported family income and family size, using the 2004 poverty thresholds published by the U.S. Census Bureau, and 2016 estimates are based on reported family income and family size, using the 2015 poverty thresholds published by the U.S. Census Bureau.

${ }^{\$}$ Northeast: Connecticut, Maine, Massachusetts, New Hampshire, New Jersey, New York, Pennsylvania, Rhode Island, and Vermont. Midwest: Illinois, Indiana, Iowa, Kansas, Michigan, Minnesota, Missouri, Nebraska, North Dakota, Ohio, South Dakota, and Wisconsin. South: Alabama, Arkansas, Delaware, District of Columbia, Florida, Georgia, Kentucky, Louisiana, Maryland, Mississippi, North Carolina, Oklahoma, South Carolina, Tennessee, Texas, Virginia, and West Virginia. West: Alaska, Arizona, California, Colorado, Hawaii, Idaho, Montana, Nevada, New Mexico, Oregon, Utah, Washington, and Wyoming. 5 Private coverage: Includes adults who had any comprehensive private insurance plan (including health maintenance organizations and preferred provider organizations). Medicaid: For adults aged $<65$ years, includes adults who do not have private coverage, but who have Medicaid or other state-sponsored health plans including Children's Health Insurance Program (CHIP). For adults aged $\geq 65$ years, includes adults who do not have any private coverage but have Medicare and Medicaid or other state-sponsored health plans including CHIP; Medicare only: Includes older adults who only have Medicare coverage; Other coverage: Includes adults who do not have private insurance, Medicaid, or other public coverage, but who have any type of military coverage or Medicare (for those aged $<65$ years). This category also includes adults who are covered by other government programs. Uninsured: Includes adults who have not indicated that they are covered at the time of the interview under private health insurance, Medicare, Medicaid, CHIP, a state-sponsored health plan, other government programs, or military coverage.
}

** Disability/limitation was defined based on self-reported presence of selected impairments including vision, hearing, cognition, and movement. Limitations in performing activities of daily living was defined based on response to the question, "Does [person] have difficulty dressing or bathing?" Limitations in performing instrumental activities of daily living was defined based on response to the question, "Because of a physical, mental, or emotional condition, does [person] have difficulty doing errands alone such as visiting a doctor's office or shopping?" Any disability/limitation was defined as a "yes" response pertaining to at least one of the disabilities/limitations listed (e.g., vision, hearing, cognition, movement, activities of daily living, or instrumental activities of daily living). A random sample of half the respondents from the 2016 Person File were asked about disability/limitation. Disability/limitation estimates (\%, population estimate) were obtained using the specific adult disability weight.

†† Starting in 2013, sexual orientation questions were added to NHIS for the first time. To determine sexual orientation, adult respondents were asked, "Which of the following best represents how you think of yourself?" with a response options of gay ("lesbian or gay" for female respondents), straight, that is, "not gay" ("not lesbian or gay" for female respondents), bisexual, something else, and I don't know the answer.

$\$ \$$ The six-question K6 scale was developed to identify persons with a high likelihood of having a diagnosable mental illness and associated functional limitations. The K6 scale asked how often during the past 30 days the respondents felt a) so sad that nothing could cheer them up; b) nervous; c) restless or fidgety; d) hopeless; e) that everything was an effort; and f) worthless. Responses were on a five-point Likert scale ranging from none of the time to all of the time. For each question, a value of zero, one, two, three, or four was assigned to the response "none of the time," "a little of the time," "some of the time," "most of the time," or "all of the time," respectively. Responses to the six items were summed to yield a K6 score between 0 and 24, with a score of 13 or higher indicating serious psychological distress. Additional information available at https://www.cdc. gov/nchs/data/databriefs/db203.pdf.

The MMWR series of publications is published by the Center for Surveillance, Epidemiology, and Laboratory Services, Centers for Disease Control and Prevention (CDC), U.S. Department of Health and Human Services, Atlanta, GA 30329-4027.

Suggested citation: [Author names; first three, then et al., if more than six.] [Report title]. MMWR Morb Mortal Wkly Rep 2018;67:[inclusive page numbers].

\section{Centers for Disease Control and Prevention \\ Brenda Fitzgerald, MD, Director \\ Leslie Dauphin, PhD, Acting Associate Director for Science \\ Joanne Cono, MD, ScM, Director, Office of Science Quality}

Chesley L. Richards, MD, MPH, Deputy Director for Public Health Scientific Services

Michael F. Iademarco, MD, MPH, Director, Center for Surveillance, Epidemiology, and Laboratory Services

\section{MMWR Editorial and Production Staff (Weekly) \\ Sonja A. Rasmussen, MD, MS, Editor-in-Chief}

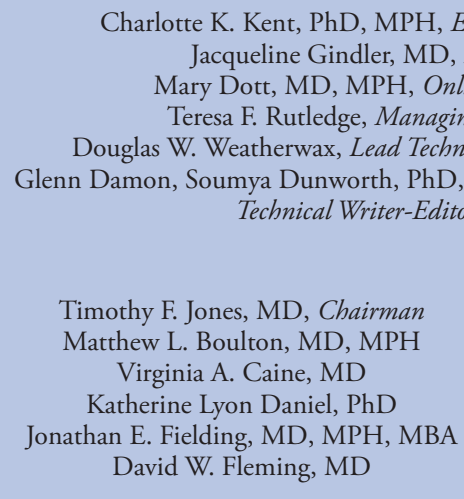

Charlotte K. Kent, PhD, MPH, Executive Editor

Jacqueline Gindler, MD, Editor

Mary Dott, MD, MPH, Online Editor

Teresa F. Rutledge, Managing Editor

Douglas W. Weatherwax, Lead Technical Writer-Editor

Technical Writer-Editors

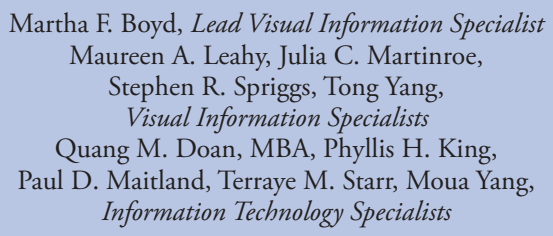

MMWR Editorial Board

\author{
Jeff Niederdeppe, $\mathrm{PhD}$ \\ Patricia Quinlisk, MD, MPH \\ Patrick L. Remington, MD, MPH \\ Carlos Roig, MS, MA \\ William L. Roper, MD, MPH \\ William Schaffner, MD
}


Differences between groups were assessed using a Wald F test, with statistical significance defined as $\mathrm{p}<0.05$. Population counts were estimated from extrapolated probability weights, rounded down to the nearest 10,000 persons. Quit ratios were calculated overall and by age group. Logistic regression was used to assess overall trends in prevalence, cigarettes smoked per day, and quit ratios during 2005-2016, controlling for sex, age, and race/ethnicity. T-tests were performed to examine differences between 2015 and 2016.

In 2016, $15.5 \%$ (37.8 million) of U.S. adults were current cigarette smokers (Table). Overall, smoking prevalence did not change significantly from 2015 (15.1\%) to 2016 (15.5\%). Current cigarette smoking prevalence was higher among males (17.5\%) than among females (13.5\%). By age group, prevalence was higher among adults aged $25-44$ years $(17.6 \%)$ and $45-64$ years $(18.0 \%)$ than among those aged $18-24$ years $(13.1 \%)$ or $\geq 65$ years $(8.8 \%)$. Prevalence was highest among American Indian/Alaska Natives (31.8\%) and lowest among non-Hispanic Asians (9.0\%). Among adults aged $\geq 25$ years, prevalence was highest among persons with a GED (40.6\%) and lowest among those with a graduate degree (4.5\%). Prevalence was higher among persons living below the poverty level (25.3\%) than those at or above this level (14.3\%). By region, prevalence was higher in the Midwest (18.5\%) and South (16.9\%) than the West (12.3\%) or Northeast (13.3\%). By insurance status, prevalence was higher among Medicaid enrollees (25.3\%) and uninsured adults (28.4\%) than among those covered by private insurance (11.8\%), Medicare only (10.2\%), or other public insurance (19.8\%). Prevalence was higher among adults with a disability/limitation $(21.2 \%)$ than among those with no disability/limitation (14.4\%). Prevalence was higher among LGB adults (20.5\%) than among heterosexual adults (15.3\%) and among adults with serious psychological distress $(35.8 \%)$ than among those without serious psychological distress (14.7\%).

Among current smokers, the proportion of daily smokers was $76.1 \%$ in 2016, which declined from 2005 (80.8\%, p-value for trend $<0.05$ ) (data not shown). Whereas mean number of cigarettes smoked per day declined from 2005 (16.7) to 2016 (14.1) among daily smokers ( $\mathrm{p}$-value for trend $<0.05$ ), no change occurred between 2015 (14.2) and 2016 (14.1) (data not shown). During 2005-2016, increases occurred in the proportion of daily smokers who smoked 1-9 cigarettes per day (from $16.4 \%$ to $25.0 \%$ ) or $10-19$ (from $36.0 \%$ to $39.0 \%$ ) cigarettes per day (Figure 1). At the same time, decreases occurred in the proportion of daily smokers who smoked $20-29$ (from $34.9 \%$ to $28.4 \%$ ) or $\geq 30$ (from $12.7 \%$ to $7.5 \%$ ) cigarettes per day during 2005-2016 (p-value for trend $<0.05$ ). No significant changes in any category of number of cigarettes smoked per day occurred during 2015-2016.

\section{Summary}

What is already known about this topic?

The U.S. Surgeon General has concluded that the burden of death and disease from tobacco use in the United States is overwhelmingly caused by cigarettes and other combusted tobacco products. Cigarettes are the most commonly used tobacco product among U.S. adults, and about 480,000 deaths per year are caused by cigarette smoking and secondhand smoke exposure.

What is added by this report?

The proportion of U.S. adults who smoke cigarettes declined from 20.9\% in 2005 (45.1 million smokers) to $15.5 \%$ in 2016 (37.8 million smokers), but cigarette smoking prevalence did not change significantly during 2015-2016. Sociodemographic disparities in cigarette smoking persist. During 2005-2016, increases occurred in the proportion of adult ever smokers who quit smoking (50.8\% to $59.0 \%)$.

What are the implications for public health practice?

Proven population-based interventions, including tobacco price increases, comprehensive smoke-free laws, high-impact anti-tobacco media campaigns, and barrier-free access to tobacco cessation counseling and medications, are critical to reducing cigarette smoking and smoking-related disease and death among U.S. adults, particularly among subpopulations with the highest smoking prevalence.

The overall quit ratio increased from $50.8 \%$ in 2005 to $59.0 \%$ in $2016(\mathrm{p}<0.05)$. During 2005-2016, the largest increase in quit ratios occurred among adults aged 25-44 years (from $37.0 \%$ to $48.9 \%$ [p<0.05]) (Figure 2).

\section{Discussion}

During 2005-2016, the prevalence of cigarette smoking among U.S. adults declined from $20.9 \%$ to $15.5 \%$, and the proportion of ever smokers who had quit increased. However, during 2015-2016, cigarette smoking prevalence did not change significantly. In 2016, 37.8 million U.S. adults were current cigarette smokers, and marked sociodemographic differences in smoking prevalence persist. Proven populationbased interventions, including tobacco price increases, comprehensive smoke-free laws, anti-tobacco mass media campaigns, and barrier-free access to tobacco cessation counseling and medications, are critical to reduce cigarette smoking and smoking-related disease and death among U.S. adults, particularly among subpopulations with the highest prevalences.

The observed disparities in smoking prevalence are likely attributable to multiple factors (1). Racial or ethnic differences might be partly explained by sociocultural influences and norms related to the acceptability of tobacco use and variations in exposure to tobacco marketing, whereas disparities by education might be partly attributable to variations in 
TABLE. Characteristics of current adult cigarette smokers* — National Health Interview Survey, United States, 2016

\begin{tabular}{|c|c|c|c|c|c|c|}
\hline \multirow[b]{2}{*}{ Characteristic } & \multicolumn{2}{|c|}{ Males $(n=14,991)$} & \multicolumn{2}{|c|}{ Females $(n=18,037)$} & \multicolumn{2}{|c|}{ Total $(n=33,028)$} \\
\hline & $\begin{array}{l}\text { Weighted } \\
\%(95 \% \mathrm{Cl})\end{array}$ & $\begin{array}{l}\text { Population } \\
\text { estimate }^{\dagger}\end{array}$ & $\begin{array}{l}\text { Weighted } \\
\%(95 \% \mathrm{Cl})\end{array}$ & $\begin{array}{l}\text { Population } \\
\text { estimate }\end{array}$ & $\begin{array}{l}\text { Weighted } \\
\%(95 \% \mathrm{Cl})\end{array}$ & $\begin{array}{c}\text { Population } \\
\text { estimate }\end{array}$ \\
\hline Overall & $17.5(16.6-18.5)$ & $20,660,000$ & $13.5(12.8-14.3)$ & $17,110,000$ & $15.5(14.8-16.1)$ & $37,770,000$ \\
\hline \multicolumn{7}{|l|}{ Age group (yrs) } \\
\hline $18-24$ & $14.7(12.1-17.3)$ & $2,180,000$ & $11.5(9.4-13.7)$ & $1,700,000$ & $13.1(11.4-14.8)$ & $3,890,000$ \\
\hline $25-44$ & $20.6(19.0-22.3)$ & $8,480,000$ & $14.6(13.3-15.9)$ & $6,170,000$ & $17.6(16.5-18.7)$ & $14,660,000$ \\
\hline $45-64$ & $19.3(17.9-20.8)$ & $7,820,000$ & $16.8(15.5-18.0)$ & $7,190,000$ & $18.0(17.0-19.0)$ & $15,020,000$ \\
\hline$\geq 65$ & $10.1(8.8-11.5)$ & $2,160,000$ & $7.7(6.7-8.7)$ & $2,030,000$ & $8.8(8.0-9.6)$ & $4,200,000$ \\
\hline \multicolumn{7}{|l|}{ Race/Ethnicity§ } \\
\hline White & $17.8(16.8-18.8)$ & $13,570,000$ & $15.5(14.6-16.5)$ & $12,530,000$ & $16.6(15.9-17.4)$ & $26,100,000$ \\
\hline Black & $20.2(17.2-23.2)$ & $2,600,000$ & $13.5(11.5-15.5)$ & $2,130,000$ & $16.5(14.7-18.3)$ & $4,730,000$ \\
\hline Hispanic & $14.5(11.8-17.2)$ & $2,780,000$ & $7.0(5.6-8.3)$ & $1,350,000$ & $10.7(9.2-12.3)$ & $4,140,000$ \\
\hline $\mathrm{Al} / \mathrm{AN}$ & $29.3(19.3-39.4)$ & 230,000 & $34.3(24.4-44.2)$ & 260,000 & $31.8(24.1-39.5)$ & 490,000 \\
\hline Asian & $14.0(10.7-17.3)$ & 910,000 & $4.6(2.8-6.4)$ & 340,000 & $9.0(7.1-10.9)$ & $1,260,000$ \\
\hline Multirace & $27.7(19.9-35.5)$ & 520,000 & $22.9(16.5-29.2)$ & 460,000 & $25.2(20.4-30.0)$ & 990,000 \\
\hline \multicolumn{7}{|l|}{ Education level ${ }^{* *}$} \\
\hline $0-12$ yrs (no diploma) & $28.9(25.7-32.1)$ & $3,760,000$ & $19.5(17-22)$ & $2,590,000$ & $24.1(22.1-26.2)$ & $6,360,000$ \\
\hline$\leq 8$ th grade & $22.4(16.9-27.8)$ & $1,100,000$ & $10.4(7.7-13.1)$ & 530,000 & $16.2(13.3-19.2)$ & $1,630,000$ \\
\hline 9 th-11th grade & $35.1(30.4-39.8)$ & $2,070,000$ & $26.2(22.5-29.8)$ & $1,530,000$ & $30.7(27.6-33.7)$ & $3,610,000$ \\
\hline 12th grade (no diploma) & $26.7(20.7-32.8)$ & 580,000 & $22.8(14.8-30.9)$ & 520,000 & $24.8(19.8-29.7)$ & $1,100,000$ \\
\hline GED & $45.5(38.7-52.2)$ & $1,350,000$ & $36.1(30.1-42.0)$ & $1,140,000$ & $40.6(36.1-45.1)$ & $2,490,000$ \\
\hline High school graduate & $23.1(21.1-25.1)$ & $5,120,000$ & $16.5(14.9-18.2)$ & $3,860,000$ & $19.7(18.4-21.1)$ & $8,980,000$ \\
\hline Some college (no degree) & $19.8(17.6-22.1)$ & $3,420,000$ & $18.1(16.4-19.8)$ & $3,370,000$ & $18.9(17.6-20.3)$ & $6,790,000$ \\
\hline Associate degree & $17.1(14.7-19.6)$ & $1,990,000$ & $16.4(14.4-18.5)$ & $2,330,000$ & $16.8(15.2-18.3)$ & $4,330,000$ \\
\hline Undergraduate degree & $9.1(7.7-10.5)$ & $1,990,000$ & $6.4(5.4-7.5)$ & $1,530,000$ & $7.7(6.8-8.6)$ & $3,520,000$ \\
\hline Graduate degree & $5.5(4.1-6.9)$ & 730,000 & $3.5(2.5-4.5)$ & 510,000 & $4.5(3.6-5.3)$ & $1,250,000$ \\
\hline \multicolumn{7}{|l|}{ Poverty status $^{\dagger \dagger}$} \\
\hline At or above poverty level & $16.4(15.4-17.3)$ & $16,380,000$ & $12.3(11.5-13.0)$ & $12,650,000$ & $14.3(13.6-14.9)$ & $29,030,000$ \\
\hline Below poverty level & $28.8(25.8-31.9)$ & $3,500,000$ & $22.7(20.4-25.0)$ & $3,770,000$ & $25.3(23.4-27.2)$ & $7,270,000$ \\
\hline Unspecified & $14.2(10.9-17.5)$ & 770,000 & $10.2(7.5-12.8)$ & 690,000 & $12.0(9.8-14.1)$ & $1,470,000$ \\
\hline \multicolumn{7}{|l|}{ U.S. Census region§§ } \\
\hline Northeast & $15.2(13.3-17.0)$ & $3,260,000$ & $11.5(9.9-13.1)$ & $2,640,000$ & $13.3(11.9-14.6)$ & $5,910,000$ \\
\hline Midwest & $19.2(17.4-20.9)$ & $4,950,000$ & $17.8(16.2-19.5)$ & $5,050,000$ & $18.5(17.2-19.7)$ & $10,000,000$ \\
\hline South & $19.7(17.9-21.5)$ & $8,310,000$ & $14.2(12.8-15.6)$ & $6,370,000$ & $16.9(15.5-18.2)$ & $14,680,000$ \\
\hline West & $14.6(13.0-16.3)$ & $4,120,000$ & $10.1(8.7-11.4)$ & $3,030,000$ & $12.3(11.1-13.4)$ & $7,160,000$ \\
\hline \multicolumn{7}{|c|}{ Health insurance coverage $\mathrm{e}^{\text {ๆๆ }}$} \\
\hline Private insurance & $13.5(12.5-14.4)$ & $10,490,000$ & $10.1(9.4-10.9)$ & $8,170,000$ & $11.8(11.1-12.4)$ & $18,670,000$ \\
\hline Medicaid & $27.7(24.5-30.9)$ & $3,260,000$ & $23.9(21.6-26.2)$ & $4,650,000$ & $25.3(23.4-27.3)$ & $7,910,000$ \\
\hline Medicare only $(\geq 65)$ & $11.8(9.4-14.2)$ & 830,000 & $9.1(7.4-10.8)$ & 910,000 & $10.2(8.8-11.7)$ & $1,750,000$ \\
\hline Other public insurance & $21.9(18.8-25.1)$ & $1,540,000$ & $17.1(14.0-20.3)$ & 970,000 & $19.8(17.4-22.2)$ & $2,510,000$ \\
\hline Uninsured & $32.8(29.5-36.1)$ & $4,270,000$ & $22.6(19.7-25.6)$ & $2,250,000$ & $28.4(26.1-30.7)$ & $6,530,000$ \\
\hline
\end{tabular}

See table footnotes on page 57 .

understanding of the range of health hazards caused by smoking $(3,4)$. Variations in access to evidence-based tobacco cessation treatments through insurance coverage might partially explain the differences observed across insurance types (5). Smoking prevalence was higher among persons with severe psychological distress $(6,7)$, potentially because of higher levels of addiction and dependence, lack of financial resources, less access to cessation treatments, and stressful living conditions among these persons $(6,7)$. Assessing the smoking status of all patients served in psychiatric inpatient and outpatient settings, integrating evidence-based cessation interventions into mental health treatment plans, and implementing tobacco-free campus policies in mental health care facilities could help reduce smoking in this population $(6,7)$.
During 2005-2016, an increasing proportion of adults who ever smoked cigarettes had quit smoking. However, following consecutive significant annual declines during 2013-2014 and 2014-2015 (8), no change in smoking prevalence was observed between 2015 and 2016. Moreover, longstanding declines in the proportion of daily smokers who smoked $\geq 20$ cigarettes per day have stalled in recent years. These findings could be the result of multiple factors, including slowed progress in the adoption of proven interventions (9), or increased nicotine dependence from the concurrent use of other tobacco products (1). These findings underscore the importance of enhanced and sustained implementation of proven population-level interventions to continue previously observed annual declines in adult cigarette smoking (2). 
TABLE. (Continued) Characteristics of current adult cigarette smokers* — National Health Interview Survey, United States, 2016

\begin{tabular}{|c|c|c|c|c|c|c|}
\hline \multirow[b]{2}{*}{ Characteristic } & \multicolumn{2}{|c|}{ Males $(n=14,991)$} & \multicolumn{2}{|c|}{ Females $(n=18,037)$} & \multicolumn{2}{|c|}{ Total $(n=33,028)$} \\
\hline & $\begin{array}{l}\text { Weighted } \\
\%(95 \% \mathrm{Cl})\end{array}$ & $\begin{array}{l}\text { Population } \\
\text { estimate }^{\dagger}\end{array}$ & $\begin{array}{l}\text { Weighted } \\
\%(95 \% \mathrm{Cl})\end{array}$ & $\begin{array}{l}\text { Population } \\
\text { estimate }\end{array}$ & $\begin{array}{l}\text { Weighted } \\
\%(95 \% \mathrm{Cl})\end{array}$ & $\begin{array}{c}\text { Population } \\
\text { estimate }\end{array}$ \\
\hline \multicolumn{7}{|l|}{ Disability/Limitation*** } \\
\hline Yes & $25.5(22.8-28.2)$ & $2,470,000$ & $18.0(16.1-20.0)$ & $2,320,000$ & $21.2(19.6-22.9)$ & $4,790,000$ \\
\hline $\begin{array}{l}\text { No } \\
\text { Sexual orientationtt† }\end{array}$ & $16.4(15.3-17.6)$ & $6,360,000$ & $12.6(11.6-13.6)$ & $5,630,000$ & $14.4(13.6-15.2)$ & $11,990,000$ \\
\hline Straight & $17.3(16.3-18.2)$ & $19,230,000$ & $13.5(12.7-14.2)$ & $15,920,000$ & $15.3(14.6-16.0)$ & $35,160,000$ \\
\hline Gay/Lesbian/Bisexual & $23.8(17.6-30.1)$ & 620,000 & $17.9(13.8-22.0)$ & 600,000 & $20.5(16.7-24.3)$ & $1,230,000$ \\
\hline \multicolumn{7}{|c|}{ Serious psychological distress (Kessler Scale) (§§§ $^{\S}$} \\
\hline Yes & $39.3(33.3-45.2)$ & $1,290,000$ & $33.6(28.8-38.5)$ & $1,720,000$ & $35.8(32.1-39.6)$ & $3,010,000$ \\
\hline No & $16.8(15.9-17.8)$ & $18,610,000$ & $12.7(11.9-13.5)$ & $14,850,000$ & $14.7(14.0-15.4)$ & $33,460,000$ \\
\hline
\end{tabular}

Abbreviations: Al/AN = American Indian/Alaska Native; $\mathrm{Cl}=$ confidence interval; GED = General Education Development certificate.

* Persons who reported smoking $\geq 100$ cigarettes during their lifetime and who, at the time of interview, reported smoking every day or some days. Excludes 111 respondents whose smoking status was unknown.

† Population estimates are calculated from extrapolated probability weights and are rounded down to the nearest 10,000 persons. Therefore, they may not add up to the overall population estimate.

$\S$ Excludes 89 respondents of non-Hispanic unknown race. Unless otherwise indicated, all racial/ethnic groups are non-Hispanic; Hispanics can be of any race.

I Does not include Native Hawaiians or Other Pacific Islanders.

** Among persons aged $\geq 25$ years. Excludes 107 persons whose education level was unknown.

${ }^{t \dagger}$ Family income is reported by the family respondent who might or might not be the same as the sample adult respondent from whom smoking information is collected. 2016 estimates are based on reported family income and family size, based on the 2015 poverty thresholds published by the U.S. Census Bureau.

$\S \S$ Northeast: Connecticut, Maine, Massachusetts, New Hampshire, New Jersey, New York, Pennsylvania, Rhode Island, and Vermont; Midwest: Illinois, Indiana, lowa, Kansas, Michigan, Minnesota, Missouri, Nebraska, North Dakota, Ohio, South Dakota, and Wisconsin; South: Alabama, Arkansas, Delaware, District of Columbia, Florida, Georgia, Kentucky, Louisiana, Maryland, Mississippi, North Carolina, Oklahoma, South Carolina, Tennessee, Texas, Virginia, and West Virginia; West: Alaska, Arizona, California, Colorado, Hawaii, Idaho, Montana, Nevada, New Mexico, Oregon, Utah, Washington, and Wyoming.

กๆ Private coverage: Includes adults who had any comprehensive private insurance plan (including health maintenance organizations and preferred provider organizations). Medicaid: For adults aged $<65$ years, includes adults who do not have private coverage, but who have Medicaid or other state-sponsored health plans including Children's Health Insurance Program (CHIP). For adults aged $\geq 65$ years, includes adults who do not have any private coverage but have Medicare and Medicaid or other state-sponsored health plans including CHIP; Medicare only: Includes older adults who only have Medicare coverage; Other coverage: Includes adults who do not have private insurance, Medicaid, or other public coverage, but who have any type of military coverage or Medicare (for those aged $<65$ years). This category also includes adults who are covered by other government programs. Uninsured: Includes adults who have not indicated that they are covered at the time of the interview under private health insurance, Medicare, Medicaid, CHIP, a state-sponsored health plan, other government programs, or military coverage.

*** Disability/limitation was defined based on self-reported presence of selected impairments including vision, hearing, cognition, and movement. Limitations in performing activities of daily living was defined based on response to the question, "Does [person] have difficulty dressing or bathing?" Limitations in performing instrumental activities of daily living was defined based on response to the question, "Because of a physical, mental, or emotional condition, does [person] have difficulty doing errands alone such as visiting a doctor's office or shopping?" Any disability/limitation was defined as a "yes" response pertaining to at least one of the disabilities/limitations listed (e.g., vision, hearing, cognition, movement, activities of daily living, or instrumental activities of daily living). A random sample of half the respondents from the 2016 Person File were asked about disability/limitation. Disability/limitation estimates (\%, population estimate) were obtained used the specific adult disability weight.

${ }^{++\dagger}$ Response options provided on the National Health Interview Survey were "straight, that is, not gay" for men, and "straight, that is, not gay or lesbian" for women.

$\S \S \S$ The Kessler psychological distress scale is a series of six questions that ask about feelings of sadness, nervousness, restlessness, worthlessness, and feeling like everything is an effort in the past 30 days. Participants were asked to respond on a Likert Scale ranging between "None of the time" (score $=0$ ) and "All of the time" (score $=4)$. Responses were summed over the six questions; any person with a score of $\geq 13$ was coded as having serious psychological distress, and respondents with a score $<13$ were coded as not having serious psychological distress.

The findings in this report are subject to at least five limitations. First, smoking status was self-reported and not validated by biochemical testing; however, self-reported smoking status is correlated with serum cotinine levels (10). Second, because NHIS does not include institutionalized populations and persons in the military, results are not generalizable to these groups. Third, the NHIS response rate of $54.3 \%$ might have resulted in nonresponse bias, even after adjustment for nonresponse. Fourth, the assessment of broad racial/ethnic populations (e.g., Asians and Hispanics) can mask differences in smoking prevalence among subgroups of these populations. 99 Finally, these estimates might differ from those reported from other surveys. These differences can be partially explained by varying survey

\footnotetext{
99 https://www.cdc.gov/mmwr/volumes/65/wr/mm6530a1.htm.
}

methodologies and definitions of current smoking; however, trends in prevalence are comparable across surveys (1).

Sustained implementation of comprehensive state tobacco control programs can accelerate progress toward reducing adult smoking prevalence (2). Targeted interventions are warranted to reach subpopulations with the highest incidence of use, and can result in substantial reductions in tobacco-related disease and death and billions of dollars in savings from averted medical costs (1).

\section{Conflict of Interest}

No conflicts of interest were reported.

${ }^{1}$ Office on Smoking and Health, National Center for Chronic Disease Prevention and Health Promotion, CDC.

Corresponding author: Ahmed Jamal, AJamal@cdc.gov, 770-488-5493. 
FIGURE 1. Percentage of daily smokers* aged $\geq 18$ years who smoked $1-9,10-19,20-29$, and $\geq 30$ cigarettes per day - National Health Interview Survey, United States, 2005-2016

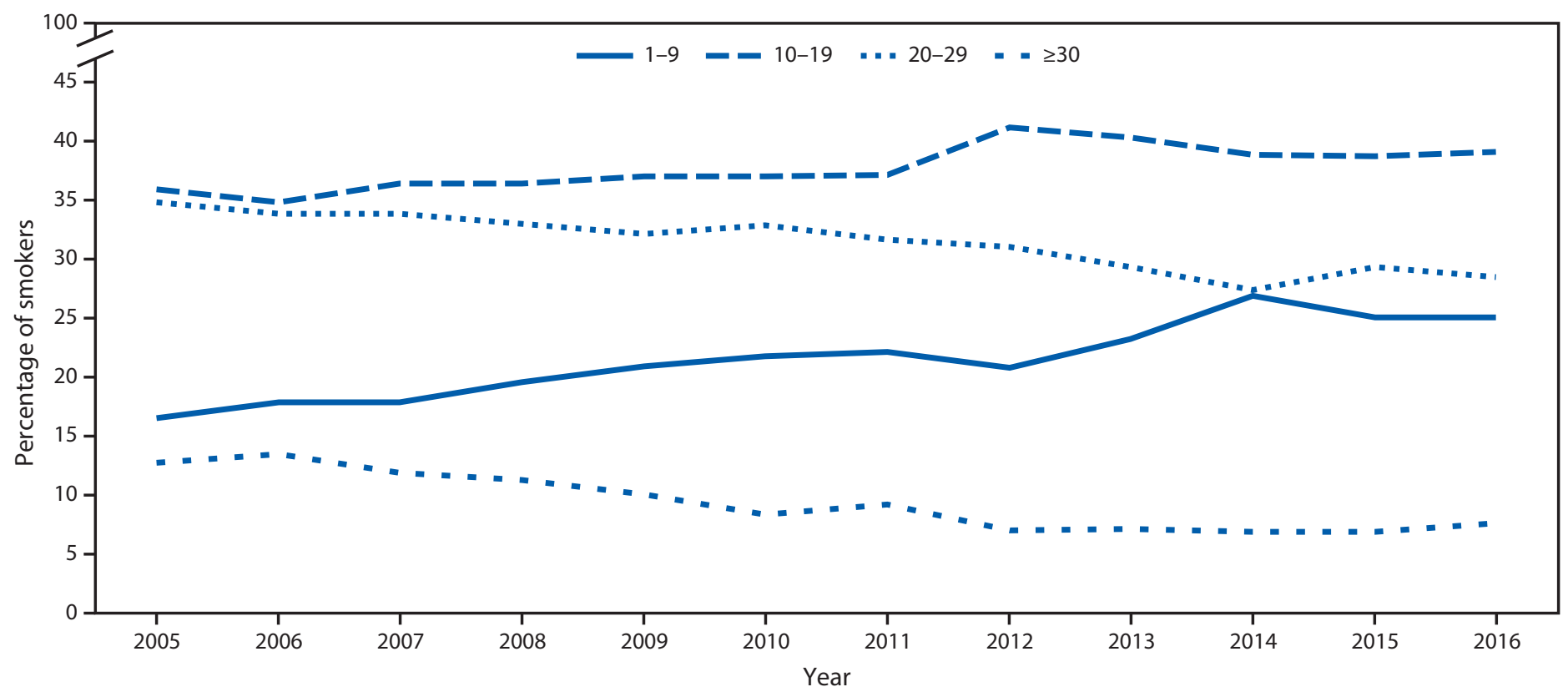

* Persons who had smoked $\geq 100$ cigarettes during their lifetime and reported smoking cigarettes every day at the time of interview.

FIGURE 2. Quit ratios* among ever smokers ${ }^{\dagger}$ aged $\geq 18$ years, overall and by age group - National Health Interview Survey, United States, $2005-2016^{\S}$

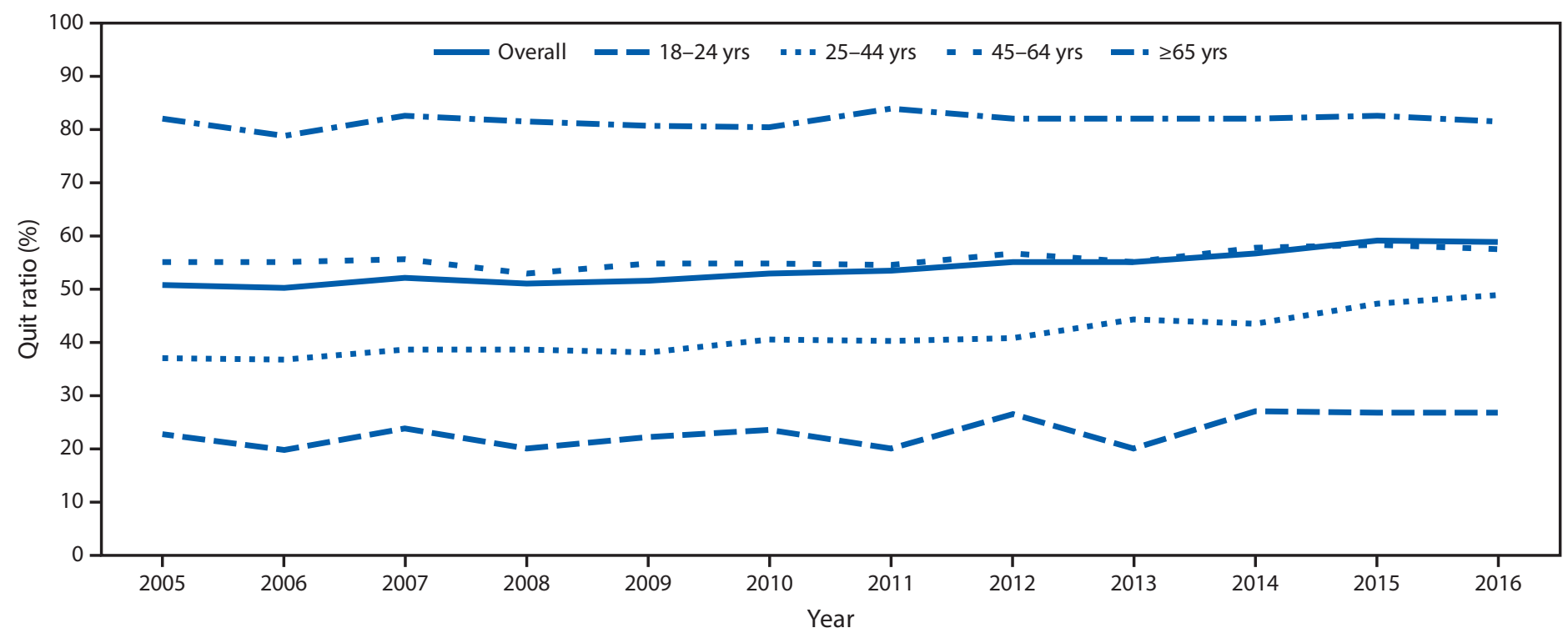

* Quit ratios defined as the ratio of former smokers to ever smokers for each survey year.

+ Respondents aged $\geq 18$ years who reported having smoked $\geq 100$ cigarettes during their lifetime.

$\S p$-value for trend 2005-2016 adjusted for sex and race/ethnicity: overall: $p<0.0001 ; 18-24$ years: $p=0.0064 ; 25-44$ years: $p<0.0001 ; 45-64$ years: $p=0.0002$; $\geq 65$ years: $p=0.0874$ 


\section{References}

1. US Department of Health and Human Services. The health consequences of smoking - 50 years of progress: a report of the Surgeon General. Atlanta, GA: US Department of Health and Human Services, CDC, Coordinating Center for Health Promotion, National Center for Chronic Disease Prevention and Health Promotion, Office on Smoking and Health, 2014. http://www.surgeongeneral.gov/library/reports/50-yearsof-progress/full-report.pdf

2. CDC. Best practices for comprehensive tobacco control programs-2014. Atlanta: US Department of Health and Human Services, CDC, National Center for Chronic Disease Prevention and Health Promotion, Office on Smoking and Health, 2014. https:/www.cdc.gov/tobacco/ stateandcommunity/best_practices/index.htm

3. Siahpush M, McNeill A, Hammond D, Fong GT. Socioeconomic and country variations in knowledge of health risks of tobacco smoking and toxic constituents of smoke: results from the 2002 International Tobacco Control (ITC) Four Country Survey. Tob Control 2006;15(Suppl 3):iii65-70. https://doi.org/10.1136/tc.2005.013276

4. Pampel FC, Krueger PM, Denney JT. Socioeconomic disparities in health behaviors. Annu Rev Sociol 2010;36:349-70. https://doi.org/10.1146/ annurev.soc.012809.102529
5. McAfee T, Babb S, McNabb S, Fiore MC. Helping smokers quitopportunities created by the Affordable Care Act. N Engl J Med 2015;372:5-7. https://doi.org/10.1056/NEJMp1411437

6. American Legacy Foundation. A hidden epidemic: tobacco use and mental illness. Washington, DC: American Legacy Foundation; 2011.

7. Gfroerer J, Dube SR, King BA, et al. Vital signs: current cigarette smoking among adults aged $\geq 18$ years with mental illness-United States, 2009-2011. MMWR Morb Mortal Wkly Rep 2013;62:81-7.

8. Jamal A, King BA, Neff LJ, Whitmill J, Babb SD, Graffunder CM. Current cigarette smoking among adults_-United States, 2005-2015. MMWR Morb Mortal Wkly Rep 2016;65:1205-11. https://doi. org/10.15585/mmwr.mm6544a2

9. Holmes CB, King BA, Babb SD. Stuck in neutral: stalled progress in statewide comprehensive smoke-free laws and cigarette excise taxes, United States, 2000-2014. Prev Chronic Dis 2016;13:E80. https://doi. org/10.5888/pcd13.150409

10. Binnie V, McHugh S, Macpherson L, Borland B, Moir K, Malik K. The validation of self-reported smoking status by analysing cotinine levels in stimulated and unstimulated saliva, serum and urine. Oral Dis 2004;10:287-93. https://doi.org/10.1111/j.1601-0825.2004.01018.x 